\title{
STANDARD ISOLATION PRECAUTIONS EDUCATIONAL INTERVENTION ON UNDER GRADUATE MEDICAL STUDENTS OF ZAGAZIG UNIVERSITY \\ By
}

Eman E. Orabi

Public Health and Community Medicine Department-Zagazig University-Egypt

Corresponding author,

Eman E. Orabi

Email: -

dr.eman.elshahat@gmail.com
Background Standard Precautions is the primary strategy and foundation for Successful hospital acquired infection control. The routine implementation of standard precautions greatly reduces the risk of nosocomial infections in the absence of a definitive diagnosis. The aim of this study was to estimate the effect of an educational intervention program on standard isolation precautions on knowledge, attitude of medical students of Zagazig University. Methods: An interventional study was used. Setting: The study was conducted at faculty of Medicine Zagazig University. Sample: The study sample consisted of 135 medical students in Zagazig University. Tools: Data was collected through: An interviewing questionnaire to assess sociodemographic characteristics of participants, their knowledge and attitude before and after educational intervention regarding standard isolation precautions. Results: The majority of studied sample has significant improvement in knowledge and attitude towards standard isolation precautions $(\mathrm{p}<0.05)$ after implementation of the health education program. The total knowledge and intention to change practice of the participants regarding standard isolation precautions showed statistically significant improvements after the intervention ( $92 \%$ and $74.9 \%$ ) respectively after the intervention compared with $(18.5 \%$ and $42.3 \%)$ respectively before intervention( $\mathrm{p}<0.001)$. Conclusion and recommendation: This study concluded that health education about standard isolation precautions improved knowledge and attitude of the studied medical students, so more interventions are needed to increase the knowledge about SIPs and Infection Control among medical students.

Keywords: health education program, standard isolation precautions, infection control, medical students

\section{INTRODUCTION}

$I^{n}$ nfection prevention and control measures aim to ensure the protection of those who might be vulnerable to acquiring an infection both in the general community and while receiving care due to health problems, in a range of settings. The basic principle of infection prevention and control is hygiene (1).

In USA, approximately 99,000 deaths occur per year with hospital acquired infections. In France, the prevalence of hospital acquired infections was $6.87 \%$ in 2001 and $7.5 \%$ in 2006. In Italy in 2000's, about $6.7 \%$ of hospitalized patients was infected. The overall nosocomial infection rate at Saudi Arabian Military hospital was 4.98 per 100 discharged patients. $(\mathbf{2}, \mathbf{3}, \mathbf{4})$

After construction of an infection control unit, Research Institute in Egypt conducted a surveillance program in a period from September to December 2001and the same periods in 2004 found that the overall nosocomial infection rates were $12.6 \%$ and $5.8 \%$ respectively. (5 ).The recently released Egyptian Demographic Health Survey reported that the overall prevalence of antibody to $\mathrm{HCV}$ is $14.7 \%$. (6).

Center for Disease Control proposed a series of procedures that healthcare workers should comply with for all patients regardless of their diagnoses, these precautions known as standard precautions (SPs). (7).

Standard precautions mean treating all patients in health care facility with the same level of standard precautions involves work practices that are essential to provide a high level of protection to patient, health care workers and visitors. (8). 
SPs are the minimum level of infection control required in the treatment and care of all patients. These include personal hygiene practices, particularly hand washing; use of personal protective equipment such as gloves, gown and protective eyewear; aseptic technique; safe disposal system for sharps and contaminated matter, adequate sterilization of reusable equipment and environmental control. (9).

Non compliance with SPs has been postulated to be determined by a range of factors including lack of knowledge, lack of resources and training opportunities, excessive workload and interference with flow of work. (10).

Medical students are at particular risk of exposure to blood-borne pathogens, due to their limitedexperience in performing invasive procedures. ( 11). So, Assessing medical students' knowledge as regard standard precautions will aid in prevention of nosocomial infections and can help in reform the curriculam providing the adequate knowledge and skills. (12).

The goals of infection control and prevention training program are to educate health professionals in how pathogens can be transmitted, apply current scientifically accepted infection control principles and minimize opportunity for transmission of pathogens. (13)

Aim of this study is to outline a program to improve knowledge, attitude of medical students towards standard isolation precautions in Faculty of Medicine Zagazig University.

\section{-Subjects and Methods}

\section{I-Technical design:}

1-Site: The study was conducted at Faculty of Medicine Zagazig University

2-Subjects: The target populations of this study was medical students who started their practical training, $4^{\text {th }}, 5$ th, and $6^{\text {th }}$ grades at Faculty of Medicine Zagazig University

- Inclusion criteria: The students in $4^{\text {th }}, 5$ th, and $6^{\text {th }}$ grades as they started their practical training and actual dealing with patients in educational hospitals.

- Exclusion criteria: The students in $1^{\text {st }}, 2^{\text {nd }}$, and $3^{\text {rd }}$ grades did not participate in the study as they haven't started their practical training yet.

\section{3-Sampling and sample size:}

Sample size was calculated by using Epi-info version 6 assuming that percent of change of knowledge after health education program was \%25. (14) at 95\% confidence level, and $80 \%$ power and non response rate $10 \%$.Total number of medical students in $4^{\text {th }}$, 5th, and $6^{\text {th }}$ grades in 2015 was 2850 (Faculty of Medicine Zagazig University Records, 2015). The sample was (135). Stratified random technique used with putting proportional allocation into consideration in selection of the sample of the students from each grade. The ratio between number of students in grades $\left(4^{\text {th }}\right.$, 5 th, and $6^{\text {th }}$ ) is relatively equal so, 45 student randomly selected from each grade.

\section{4-Tools}

A-Questionnaire for collecting some personal and socioeconomic level of selected sample.

B-Pre and post test questionnaire for assessment of knowledge and attitude of the students

C-Health education message which include the answer of questions of pretest questionnaire, the message will be conducted through booklets

\section{II_Operational design:}

1-Type of study: An intervention study (pre post intervention).

2-Time: The study carried out during the year (2016-2017)

\section{3-Stages:}

\section{Stage I:}

A_Pilot stage: -Pilot study was conducted on 15 participant (who not included in the study) to test the feasibility and practicability of the tools used in the study.

Test of validity of the questionnaire and reliability was tested by cronbach's test 0.77

B_ Pretest questionnaire: - Assessment of knowledge and attitude of medical students towards standard isolation precautions by pretest questionnaire before intervention. The questionnaire filled by the students, the average time to complete the questionnaire ranged from 15-20 minutes.

Questionnaire:

First part: 
i- Personal characteristics as sex, residence, grade, received training course

ii-Socioeconomic data

Scoring system of socioeconomic data.(15) classified to high, middle, low.

The total score was 37

Scores from 31-37 were considered high social score.

Scores from 25-30 were considered middle social score.

Scores less than 24 were considered low social score.

Second part:

A-Knowledge

Scoring system for Knowledge

The questions are 2 types open, closed Questions.

A-open question: scoring as following: correct and complete answer score $=2$, correct but incomplete answer score $=1$, incorrect answer score $=$ zero.

B-Closed Questions: scoring as following correct score $=1$ and incorrect answer score= zero.

Questions about knowledge of each one of 8 items of standard isolation precautions:

1- Hand washing and antisepsis (hand hygiene).(6 open questions total score $=12)$

Types, minimum time for the procedure, types of antiseptics used, indication of routine, hygienic and surgical hand washing

2- Personal protective equipments. $(2$ open questions total score $=4$ )

Types of PPE and types of gloves

3- Aseptic techniques. (3 questions, Two closed questions and one open question total score $=4$ )

The Aseptic Non Touch Technique (ANTT) and Preparation before injection

3- Sterilization and disinfection. (4 open questions total score $=8$ )

Methods of decontamination, Methods of cleaning, Methods of Disinfection, Principal sterilization method

4- Environmental Managements Practices. (2 open questions total score $=4$ )

Frequency of cleaning in different areas
6- Textile and laundry ( 2 open questions total score $=4$ )

Method of cleaning of toilets and waste baskets

7- Waste Management (2 questions, one open and one closed question total score $=3$ )

Types of waste, the color coding of waste containers

8- Prevention of Needles Stick Injuries/Sharp injuries (3 questions one open questions and two closed total score $=4$ )

Discard needle in a puncture resistant safety box, characters of safety box. No recapping, bending, breaking and cutting needles.

In calculation of total knowledge of any item the scores of the questions related to that item is collected and added together and subject distributed at cut off points to classify knowledge into correct and wrong answer at 60\%. (16)

In calculation of total knowledge(total score 43) the scores of total knowledge of each item is collected and added together and subject distributed at cut off points to classify knowledge into adequate and inadequate at $60 \%$. (16) so score < 26 inadequate knowledge, score $\geq 26$ adequate knowledge.

B-Attitude (16 questions)

Each item of the 8 Standard isolation precautions has 2 Questions:

1-Attitude of the students regarding the importance of standard isolation precautions and their impact in infection control.

2- Attitude of the students regarding the intention to change practice standard isolation precautions.

\section{Scoring system for Attitude}

The questions that measure the attitude regarding the importance standard isolation precautions and their impact in infection control the score of SIP not important =zero, important $=1$, very important $=2$.

Total score $=16$, cut off point is at $60 \%$ so score $<10$ negative attitude, score $\geq 10$ positive attitude.

As regard to intention to perform action: no intention $=$ zero, intention to practice $=1$ 
Total score $=8$, cut off point is at $60 \%$, so score $<5$ inadequate intention, score $\geq 5$ inadequate intention.

Stage II (Intervention stage):

Designing a health education program (message) to the medical students. This program was conducted through a booklet designed by the researcher. This booklet contain the answers of the questions of the pretest questionnaire, it include the items of SIPs. The entire students receive the booklet. Booklets delivered to the students during 3 Sessions one for each grade, done in literature room in the hospital,45students in each $\operatorname{grade}\left(4^{\text {th }}, 5^{\text {th }}, 6^{\text {th }}\right)$ attend the sessions.

Stage III (Evaluation): Post test was done by the same tools used in the pretest using same questions of pre test questionnaire to determine change of knowledge and attitude of all the students concerning SIPs after application of message. The posttest was done 3 months after the health education sessions and takes about 3 weeks.

Field work: The actual field work started at the beginning of October 2016 and completed by the end of May, 2017.

\section{III-Administrative design and ethical consideration}

Informed verbal consents obtained from each subject before participation in the study, they reassured about the strict confidentiality of any obtained information will be used for purpose research. Official permission obtained from faculty of Medicine Zagazig University

\section{IV-Statistical Management:}

Data collected throughout prepared questionnaires and outcome measures coded, entered and analyzed using SPSS version 20.0 (Statistical Package for the Social Sciences) software for analysis. According to the type of data, the following tests were used to test differences for significance: Differences between frequencies (qualitative variables) and percentages in groups were compared by Chisquare test, in paired qualitative data by McNemmar test, correlation by Pearson's correlation. $\mathrm{P}$ value was set at $<0.05$ for significant results \& $<0.001$ for highly significant result.

\section{RESULTS}

Table (1): Some personal and socioeconomic characters of the studied group: - This table shows that about $53.3 \%$ of studied sample were male, $69.6 \%$ of them were from urban area, and 53.3 of our sample were of high socioeconomic class. About 67.4 of them not received infection control training courses, all of them willing to receive infection control training courses.

Figure (1): Distribution of the percentage of total respondent's knowledge as regard standard precautions before and after health education message among studied sample:-

This figure shows that total satisfactory knowledge significantly improved after health education session from $18.7 \%$ in pre test to $92 \%$ in post test.

Table (2): Distribution of the percentage of respondent's knowledge as regard standard precautions before and after health education message among studied sample:This table shows that there were significant improvements in all items of Standard isolation precautions but as regard sterilization and disinfection item all of studied group gave correct answer before and after intervention. The most improved item was appropriate handling of patient care equipment and soiled linen that improved from $9.6 \%$ in pre test to $71.9 \%$ in post test.

Figure (2): Assessment of the score of positive attitude as regard items of standard isolation precaution before and after health education message in the studied group:- This figure shows that there were significant improvements in the scores of positive attitude as regard items of standard isolation precaution after health education in the studied group. The most improved item was aseptic techniques which were improved from $88.6 \%$ in pre test to $96.3 \%$ in post test.

Figure( 3 ):Distribution of total intention to change practice of medical student as regard standard isolation precaution before and after health education message:- This figure shows significant improvement of adequate 
intention to change practice regarding standard isolation precaution after health education message which was improved from $42.3 \%$ in pre test to $74.9 \%$ in post test.

Table (3): Distribution of intention to change practice of medical student as regard standard isolation precaution before and after health education message:- This table shows there was highly significant improvement as regard intention to change practice of all items after health education in the studied sample as p.value $>0.001$.

Table (4): Relation between total satisfactory knowledge and some personal and socioeconomic characters of the studied group:-

This table shows that the students who had previous training and of high social class had significant satisfactory knowledge after health education message. While there were none significant association between total satisfactory knowledge and sex, residence and grade of studied medical students as p.value $>0.05$.

Table 5: Correlations between Knowledge and attitude of medical students towards standard isolation precaution:-

This table shows highly significant positive correlation between total score of knowledge and total score of attitude after health education in the studied sample as p.value $>0.001$.

\section{-Discussion}

Knowledge and adherence to, general and standard precautions are very important in the prevention of nosocomial infection. (17). So, healthcare facilities should provide specific education and training for all healthcare workers and students about infection prevention and control principles, policies and procedures that are relevant to the facility. (18). I-As regard assessment of knowledge of studied medical students about standard precautions before and after health education message:-

On assessing knowledge before intervention we found that (figure 1): only $18.5 \%$ of studied medical students had satisfactory knowledge regarding standard precautions before our intervention program. This was in agreement with the study done by (19) who found that only $27 \%$ of participating medical students reported sufficient infection control knowledge. This was in line with (20) as they noted a lack of adequate knowledge of standard precautions among physicians. Also, in agreement with our study (21) who reported that clinical instructors and supervisors need to pay adequate attention to give knowledge to students throughout their training period about measures to prevent nosocomial infections. Also, it was consistent with the study done by (22) that revealed $16.7 \%$ of studied medical students had adequate knowledge about standard precautions before intervention.

Although this was in contrast to the studies carried out by (23) and (24) which was done in UK and India which revealed that $84 \%$ of medical students in UK had satisfactory knowledge about infection control and 77.5\% of the participant students in India possessed adequate knowledge about various components of the guidelines.

These results raised concerns about medical students' knowledge about infection control. Assessing medical students' knowledge towards standard precautions will aid in prevention of nosocomial infections and can provide the foundations for curricular reform necessary to provide them with adequate knowledge and skills (25).

On assessing knowledge after intervention (Figure 1) we found that: Satisfactory knowledge significantly improves after our intervention generally, $(18.5 \%)$ in pre test of studied sample converted to $(92 \%)$ in post test gave correct answer after intervention with high statistically significant difference $(p<0.00)$, that reflect the effect of intervention and success of our educational message. These results are similar to the study done by (22) who reported that significant increase in knowledge scores about infection control from $(16.7 \%$ in pre-test to $90 \%$ in post-test, $\mathrm{P}<0.001)$. More over finding of this study showed that (table 2): corrected Knowledge about hand washing $(91.1 \%)$, sterilization $(100 \%)$ was very high 
before intervention, this can be explained by involving those items in community medicine curriculum, and low in the other items, this explained by lack of adequate knowledge. This was matched with (24) who reported that (88\%) among under graduate have appropriate knowledge regarding proper hand washing which is mixed with some misconceptions . also, (26) reported that $89.9 \%$ of the students had knowledge of hand washing before and after patient care and among respondents, and (20.9\%) did not have any knowledge toward needle bent before disposal and (27) reported that students' knowledge differed according to the specific areas, the highest scores was noticed along the domain of hand hygiene, and care of the health care providers, while sharp equipment and injuries and PPE showed the least scores . These results are compatible with findings reported from different colleges in the Middle East and Western countries (27). Also, this study was in agreement with (22) who reported that corrected Knowledge about hand washing (85. 3\%), sterilization (100\%) was very high before intervention. These results were inconsistent with (23) who showed that $58 \%$ of medical students did not know the correct indications for using alcoholic hand gel also (24) reported that Majority of under graduates knew about other aspects of infection control practices namely wearing of personal protective equipment (PPE) even when there is slightest risk of exposure to blood \& body fluids, health care workers with non-intact skin should not be involved in direct patient care until the condition resolves \& that blood spills should be promptly cleaned up, also (26) reported that the lowest percentage of correct answer (13.5\%) was in "washing before and after patient care". (28) found that medical students had rarely wash their hands after examining patients and they relay this Poor compliance on failure to learn this simple, essential behavior at medical school. Learning practices are indispensable for improving student knowledge of nosocomial infection and the prevention of infection transmission.
More over this study revealed that most improved item was Appropriate handling of patient care equipment and soiled linen the pretest adequate knowledge was (9.6\%) end elevated to $(71.9 \%)$. this may be due to low level of pre knowledge score also for clearance and simplicity of educational message regards this item. This result was similar to the study done by (22)who reported that knowledge about appropriate handling of patient care equipment and soiled linen had improved from $12 \%$ in pre test to $68 \%$ in post test.

\section{II-On assessing Positive attitude:}

As regard assessment of score of positive attitude toward standard isolation precaution before and after health education message among the studied group (figure 2): The improved items were hand washing, personal protective equipments, Sterilization and disinfection, Aseptic techniques and appropriate handling of waste .Appropriate handling of patient equipments and

Environment cleaning not significantly improve because the entire studied group had positive attitude before and after intervention. The most improved item was Aseptic techniques which improved from $89 \%$ in pre test to $96 \%$ in post test as our intervention and other educational and publicity content showed the importance of those items for patient and doctors themselves. this was in agreement with the study done by (22) that revealed improvement in positive attitude after health education intervention in most items especially as regard aseptic techniques which improved from $95 \%$ to $100 \%$ among studied medical students .

III- As regard assessment intention to change practice (table 3): this study revealed that the intention to change practice significantly improved generally after intervention (42.3\%) of participants had intention to change practice in pretest and elevated to $(74.9 \%)$ in post test. Hand washing, Sterilization and disinfection and needle and sharps injuries prevention not significantly improve as all studied group were already had intention to do them. 
Our finding was in agreement with (29) as they found that respondents had an extremely positive attitude towards disinfection procedures in their activity and universal precaution. A similar result has been observed in nurses working in operating theatre in 1taly with $96.2 \%$ that agree that guidelines for disinfection and sterilization practice should be used and maintained (30).

This is in agreement with (28) who reported that all the participants a positive attitude toward the standard tested $(\mathrm{P}<0 \quad .05)$ and $(90.9 \%)$ of the participants reported that they needed additional infection control education, especially on standard isolation precautions. Also, these results is in agreement with (26) who reported that as regard attitude, the highest and lowest rate of correct answer were shown in "wearing gloves when touching mucus membrane or non intact skin" $(90.5 \%)$ and "hand washing before and after using gloves" (40.5\%). Also, (31) as they reported significant improvement in all items of isolation and infection control positive attitude among health care workers in their study after application of intervention program in their study. (32) reported that $(92.1 \%)$ of the participants have high attitude regarding hand hygiene also comparable to $\mathbf{( 3 3 )}$ who found that $(76 \%)$ of his sample strongly agreeing on hand hygiene. (34) reported that the majority (98\%) of participant agreed with wearing gloves while performing procedures with sharp instruments. Also, this study was in agreement with (22) who reported that the intention to change practice significantly improved generally after intervention $(46 \%)$ of participants had intention to change practice in pretest and elevated to (78.6 \%) in post test. Hand washing, Sterilization and disinfection and needle and sharps injuries prevention not significantly improve as all studied group were already had intention to do them.

As regard relation between total satisfactory knowledge and some personal and socioeconomic characters of the studied group (table 4): this study reported that there was no significant role of sex, residence and grade on change of total satisfactory knowledge after health education session, while total satisfactory knowledge of studied students who had previous training infection control courses significantly improved $(93.1 \%)$ than who hadn't $(75.8 \%)(\mathrm{P}$ value $=0.015)$. Also, we found that social class affect improvement of knowledge, improvement was higher in high class $(95.8 \%)$, ( $p$ value 0.045 ) this may be due to good income and social support lead to more interest in safety and infection control issues.

This was in agreement with (35) who showed that specific training of SPs can quickly improve students' knowledge of infection control in a short period of time. Also, this study was in agreement with (22) who reported that total satisfactory knowledge of studied students who had previous training infection control courses significantly improved $(90.1 \%)$ than who hadn't $(52.5 \%)(\mathrm{P}$ value $=0.001)$ Also, social class affect improvement of knowledge, improvement was higher in high class(98.4\%), ( $\mathrm{p}$ value 0.044 )

Our finding disagreed with (27) who found significant association between total satisfactory knowledge about standard isolation precaution and grade of medical students and they reported that the total satisfactory knowledge significantly higher among those at 6 th year than in $4^{\text {th }}$ and $5^{\text {th }}$ year.

\section{Regarding correlations between Knowledge} and attitude of medical students towards standard isolation precautions (table 5)

In our study we found that there was significant positive correlation between knowledge and attitude score regard standard precaution among studied medical students and it seems rational that knowledge should have an impact on attitude .This was in agreement with (28) as they found that Spearman's correlation coefficients revealed linear positive correlations between knowledge, practice and attitude scores in the total group of medical students $(p<0.001)$, and these correlations were statistically significant within the students' level of education $(\mathrm{P}<0.004)$. However, this does not necessarily indicate that the better the knowledge, the better the attitude and the better 
the practice of infection control. While it seems rational that knowledge and attitude should have an impact on practice, no change will be observed if it is not

possible to comply with existing recommendations, for instance, due to lack of gowns or gloves. More over our finding agreed with (36) showed a positive correlation between knowledge and performance of SPs. And (35) reported that a positive attitude about hand disinfection was higher among health care providers with a higher level of knowledge, the educational background is one of the factors influencing compliance with good practices and education works synergistically with other factors namely behavior and practice

Also, this study was in agreement with (22) who reported that significant positive correlation between total score of knowledge and total score of attitude after health education in the studied sample.

\section{RECOMMENDATIONS}

1- More interventions are needed to increase the knowledge about SIPs and Infection Control among our medical students.

2- All medical colleges and universities develop and evaluate a similar customized intervention for their medical students.

3-Teaching of SIPs and Infection Control principals must be involved in medical education even become obligatory subject and should be early during medical study before the initial practical period in the hospitals.

4-A written policy and infection control manual should be available for all medical students at time for practical training in Zagazig university hospitals.

5-Devoloping incentive and punishment system to medical students based on strict observation for their performance.

Table (1): Some personal and socioeconomic characters of the studied group (No. $=135)$

\begin{tabular}{|c|c|c|}
\hline & No. & $\%$ \\
\hline \multicolumn{3}{|l|}{ Sex } \\
\hline .Male & 72 & 53.3 \\
\hline .Female & 63 & 46.7 \\
\hline \multicolumn{3}{|l|}{ Residence } \\
\hline. Urban & 94 & 69.6 \\
\hline .Rural & 41 & 30.4 \\
\hline \multicolumn{3}{|c|}{ Socio economic level } \\
\hline Low & 34 & 25.2 \\
\hline .Middle & 29 & 21.5 \\
\hline .High & 72 & 53.3 \\
\hline \multicolumn{3}{|l|}{ GRADE } \\
\hline $4^{\text {th }}$ & 45 & 33.3 \\
\hline $5^{\text {th }}$ & 45 & 33.3 \\
\hline $6^{\text {th }}$ & 45 & 33.3 \\
\hline \multicolumn{3}{|c|}{ Infection control training courses } \\
\hline .Received & 44 & 32.6 \\
\hline Non received & 91 & 67.4 \\
\hline \multicolumn{3}{|c|}{ Willing to receive infection control training course } \\
\hline .YES & 135 & 100.0 \\
\hline .No & 0 & 0.0 \\
\hline
\end{tabular}


Figure (1): Distribution of the percentage of total respondent's knowledge as regard standard precautions before and after health education message among studied sample

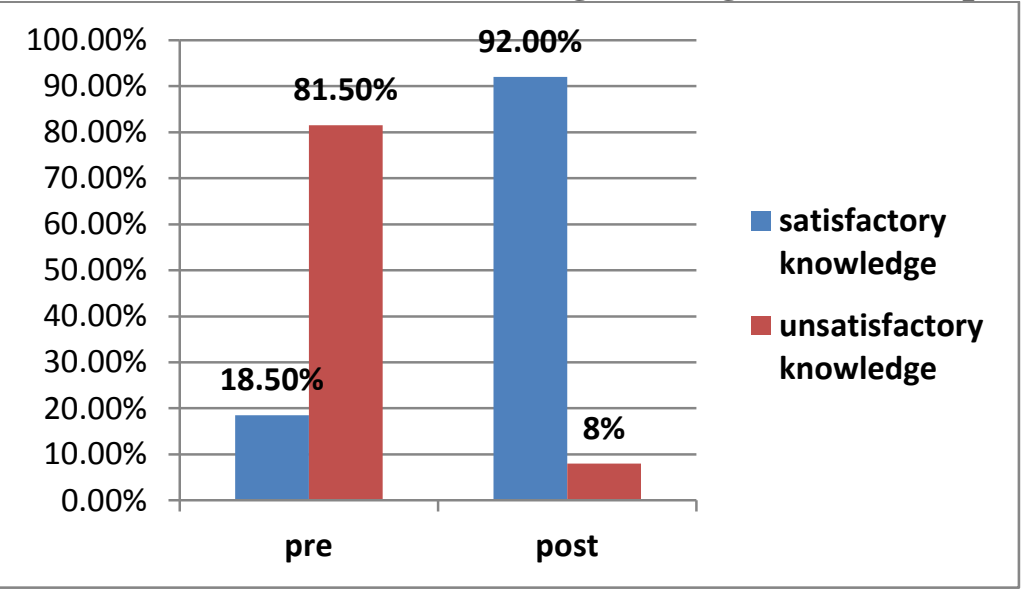

Table 2: Distribution of the percentage of respondent's knowledge as regard standard precautions before and after health education message among studied sample

\begin{tabular}{|c|c|c|c|c|c|}
\hline & \multicolumn{2}{|c|}{ PRE } & \multicolumn{2}{|c|}{ POST } & \multirow{2}{*}{$\mathbf{P}$} \\
\hline & No. & $(\%)$ & No. & $(\%)$ & \\
\hline \multicolumn{6}{|c|}{. Hand washing and antisepsis (hand hygiene) } \\
\hline Right answer & 123 & 91.1 & 134 & 99.3 & \\
\hline Wrong answer & 12 & 8.9 & 1 & 0.7 & $0.004 *$ \\
\hline \multicolumn{6}{|c|}{$\begin{array}{l}\text { Use of personal protective equipments when handling blood, body } \\
\text { substances, excretions and secretions. }\end{array}$} \\
\hline Right answer & 14 & 10.4 & 75 & 55.6 & \\
\hline Wrong answer & 121 & 89.6 & 60 & 44.4 & $0.00 * *$ \\
\hline \multicolumn{6}{|c|}{. Sterilization and disinfection. } \\
\hline Right answer & 135 & 100.0 & 135 & 100.0 & \\
\hline Wrong answer & 0 & 0.0 & 0 & 0.0 & \\
\hline \multicolumn{6}{|c|}{ Aseptic techniques. } \\
\hline Right answer & 4 & 3.0 & 45 & 33.3 & $0.00^{* *}$ \\
\hline Wrong answer & 131 & 97.0 & 90 & 66.7 & \\
\hline \multicolumn{6}{|c|}{. Environmental cleaning and spills-management. } \\
\hline Right answer & 3 & 2.2 & 75 & 55.6 & \\
\hline Wrong answer & 132 & 97.8 & 60 & 44.4 & $0.00 * *$ \\
\hline \multicolumn{6}{|c|}{. Appropriate handling of patient care equipment and soiled linen. } \\
\hline \multirow[t]{2}{*}{ Wrong answer } & 13 & 9.6 & 97 & 71.9 & $0.00 * *$ \\
\hline & 122 & 90.4 & 38 & 28.1 & \\
\hline \multicolumn{6}{|c|}{ Appropriate handling of waste. } \\
\hline Right answer & 5 & 3.7 & 57 & 42.2 & $0.00 * *$ \\
\hline Wrong answer & 130 & 96.3 & 78 & 57.8 & \\
\hline \multicolumn{6}{|c|}{. Prevention of needle of stick/sharp injuries } \\
\hline Right answer & 57 & 42.2 & 105 & 77.8 & $0.00^{* *}$ \\
\hline Wrong answer & 78 & 57.8 & 30 & 22.2 & \\
\hline
\end{tabular}

* Mc Nemar test was used 
Figure (2): Assessment of the score of positive attitude as regard items of standard isolation precaution before and after health education message in the studied group

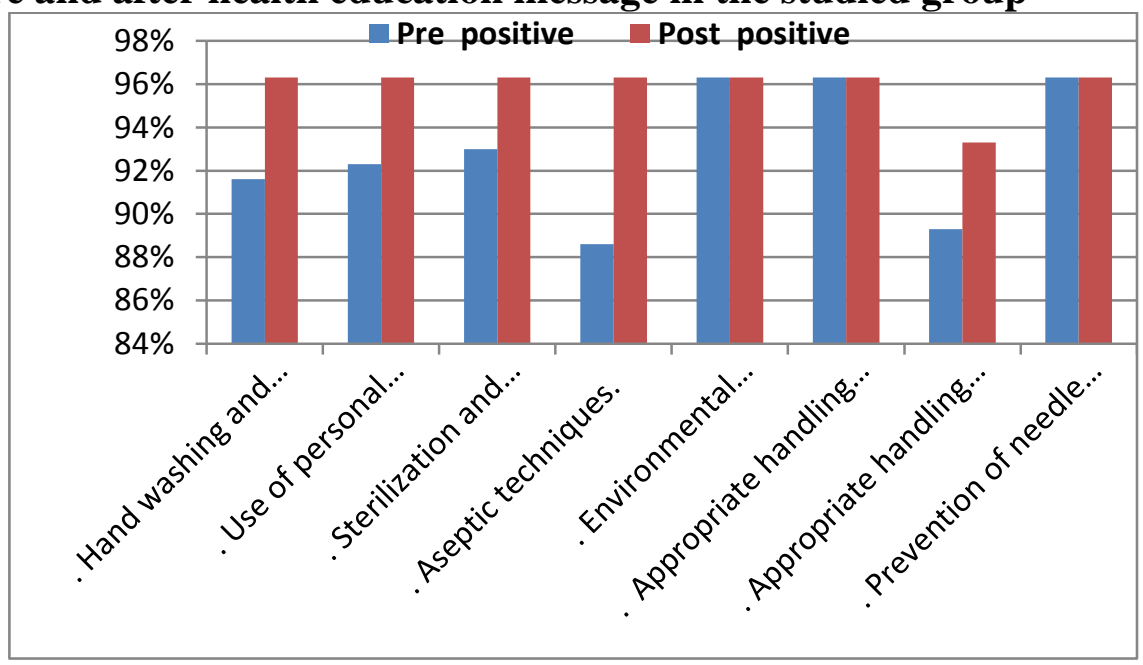

Figure (3): Distribution of total intention to change practice of medical student as regard standard isolation precaution before and after health education message.

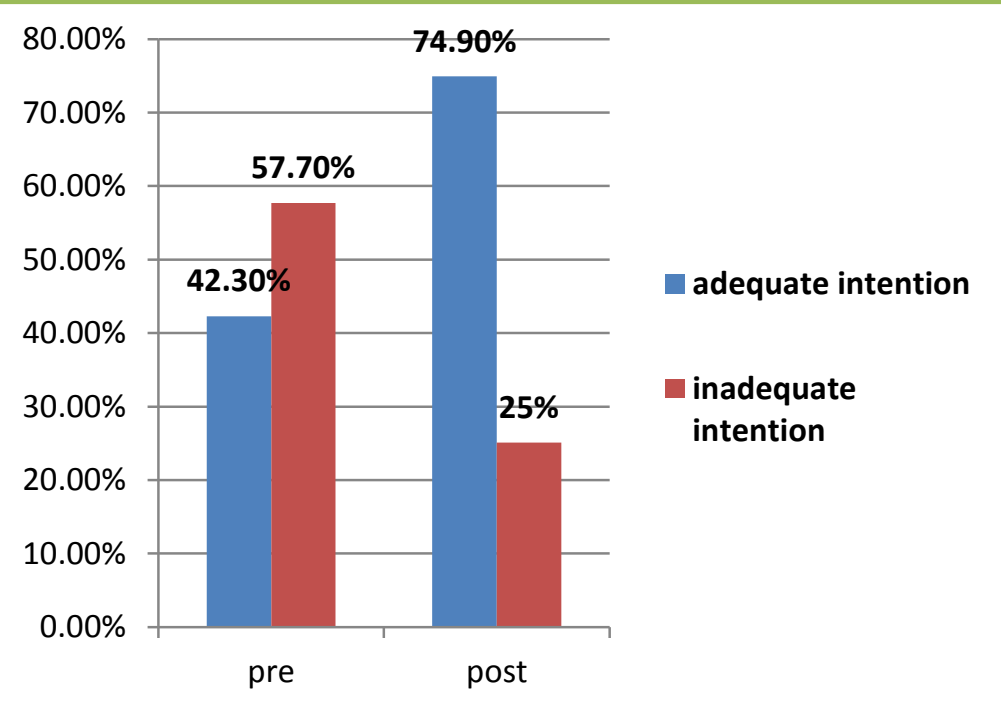


standard isolation precaution before and after health education message.

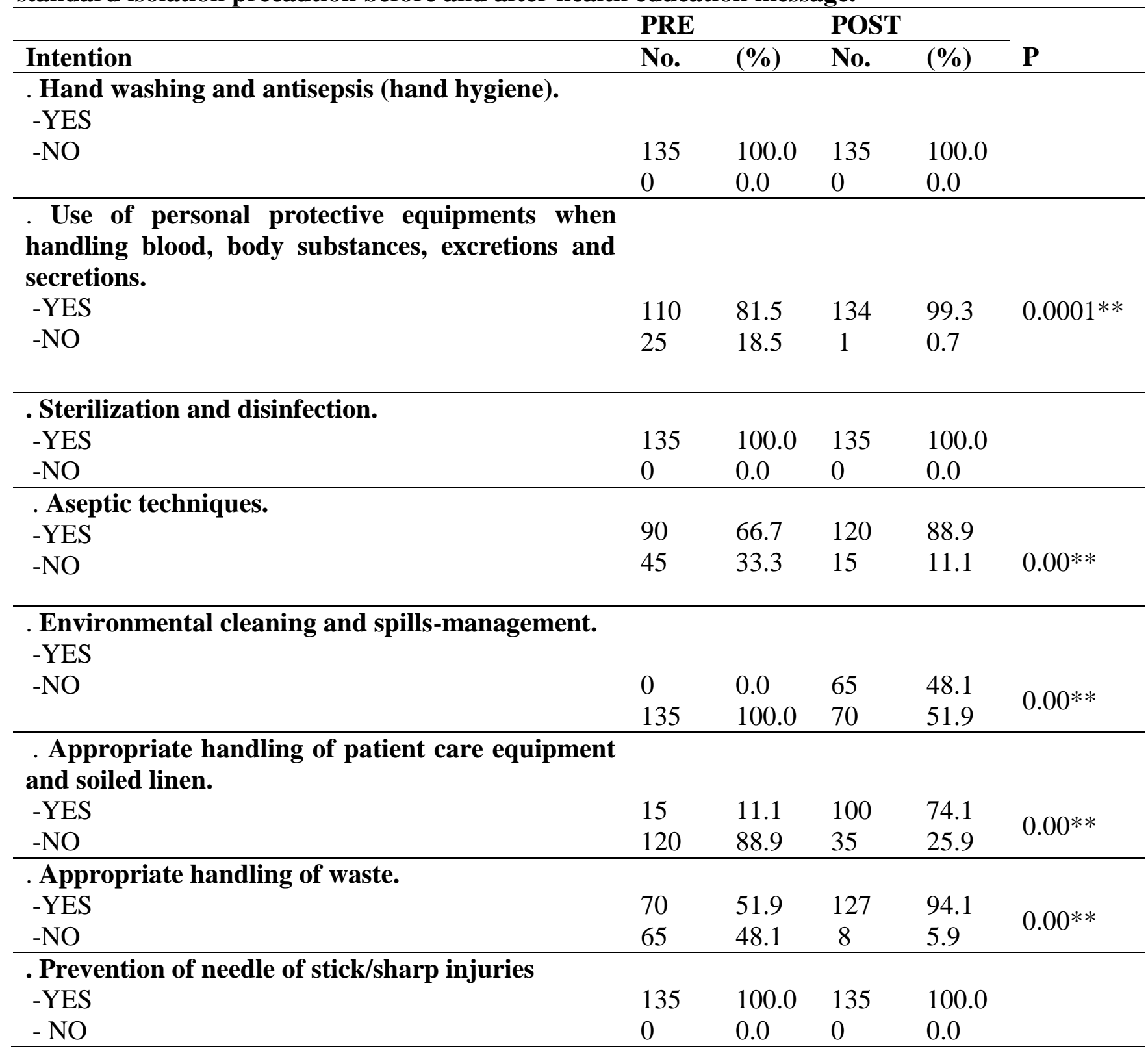

*Chi square test was used 
Table (4): Relation between total satisfactory knowledge and some personal and socioeconomic characters of the studied group

Total satisfactory knowledge Total satisfactory knowledge pre test $($ No. $=25)$

$$
\text { No. }
$$

$\%$

19.4

17.5

59

51

81.9

80.9

0.83

$\mathbf{P}$

$\%$
Sex

Female(No.=63)

Residence

- Urban

(No.=94)

- Rural

17

8

18.1

19.5

79

31

84.0

75.6

0.704

(No.=41)

Training

-Trained (No.=44)

-Not 16

trained(No.=91)

$16 \quad 36.4$

9
9.9
13.3

20.0

22.2

$\begin{array}{cc}6 & 13.3 \\ 9 & 20.0 \\ 10 & 22.2\end{array}$

34

37

39
75.6

82.2

86.7
93.1

75.8

\section{Social class}

-Low (No.=34)

-Moderate

(No.=29)

-High $($ No.=72)

6

8

9
17.6

27.6

12.5
25

16

69
73.5

55.2

95.8
0.788

(

Table 5: Correlations between Knowledge and attitude of medical students towards standard isolation precaution

\section{Total score of attitude}

Total score of knowledge

\begin{tabular}{lll}
\hline $\mathbf{r}$ & $\mathrm{P}$ & No. \\
\hline $0.469^{* *}$ & $0.000^{* *}$ & 135 \\
\hline
\end{tabular}




\section{REFERENCES}

1. World Health Organization (WHO), 2017: Infection control

2. Abd Elfatah, M. (2005): Surveillance of nososcomial infections at Saudi Arabian military hospital for one year period. German Medical Science;3:1-10.

3. Jozsef, E. (2007): L'Italie scandaliser par" I'hopital deI'horreur',Liberation,Vol.(15);19.

4. Kim, K. M., Kim, M. A., Chung, Y. S., \& Kim, N. C. (2001): Knowledge and performance of the universal precautions by nursing and medical students in Korea. Am J Infect Control; 29: 295-300.

5. World Health Organization (WHO), (2010): The global burden of health care associated infections.

6. Badawy, $H$.And EL Said, M. (2008): Changing infection control behavior in Egypt .International Jornal of Iinfection Control; 4(1):1-5.El-Zanaty and Way, 2008

7. El-Gilany, M., Whithouse, J.D., Sexton, D.J. and Kirkland, K.B. (2012): Knowledge of Health Care Providers of Standard Precautions and Infection Control at Students' Hospital, Mansoura University, Egypt,vol.(6);1-2 ,Preventive Medicine Bulletin, 2012.

8. Hoy, J. and Richmond, J.(2008): Standard precautions and infection control: HIV, viral hepatitis and STIs: a guide for primary care. Australasian Society for HIV Medicine; 146151

9. World Health Organization (WHO), (2004): Practical Guidelines for Infection Control in Health Care Facilities. Regional office for South-East Asia and Western Pacific. SEARO Regional publication No.41, WPRO Publication. WHO, 2004; 4-49.

10. Motamed, N., BabaMahmoodi, F., Khalilian, A., Peykanherati, M. and Nozari, M. (2006): Knowledge and practice of health care workers and medical students towards universal precautions in hospitals in Mazandaran Provice. East Mediterr Health J. 2006; 12(5): 653-661.

11. Hatami, H., Mohraz, M. and Azizi, F. (2001): Acquired immunodeficiency syndrome (AIDS) .Epidemiology and control of common disorders in Iran. Tehran: Eshtyagh; 589-591
12. Biberaj, P. (2014): Knowledge and Source of Information among Health Care Students on Nosocomial Infections of Medical Technical Sciences of Medical University of Tirana.pbiberaj@gmail.com

13. Mcdonald M. and Ness SH. 2015: infection control Online Continuing Education Course. Available on https://wildirismedicaleducation.com .

14. Megahed, M.E.(2012):Evaluation of infection control in primary health care centers at Zagazig district, Thesis for M.D degree.

15. El-Adawy, N.M. (2005): Knowledge and attitudes Towards Reproductive health among Mansoura University Students ;29-33.

16. Bayomy, M. (2012): Infection Control performance at Dentist Clinic in Zagazig University Hospital: MD Master Thesis. Faculty of medicine, Zagazig University.

17. Arteaga,A., Gamar-Elanbya, M.O., Jayatilleke, K., de Lourdes-Dueñas, M .A.l. and Rahma, H. (2012): International Nosocomial Infection Control Consortium (INICC) report, Am J Infect Control. 2012 Sep;42(9):942-56

18. National Health and Medical Research Council (NHMRC), (2010): Australian Guidelines for the Prevention and Control of Infection in Healthcare. Common wealth of Australia. https://www.nhmrc.gov.au

19. Phillips, G. and Ker, J. (2006): Champion students! Experience with a standardized infection control training package in medical students. JHosp Infect; 62: 518-519.

20. Bryce, E.A., Scharf, S., Walker, M., and Walsh, A. (2007). The infection control audit: the standardized audit as a tool for change. Am J Infect Control; 35, 271-283.

21. Easton, P. M., Sarma, A., Williams, F. L. R., Marwick, C. A., Phillips, G., and Nathwani, D. (2007): Infection control and management of MRSA: assessing the knowledge of staff in an acute hospital setting. J Hosp Infect; 66: 29-33. http://dx.doi.org/10.1016/j.jhin.2006.12.016

22. Alashry R., Albadawy A., Mohamed SH., (2015): Health education program about standard isolation precautions among Mansura medical students (interventional study). Master thesis in Family Medicine in Zagazig University. Mann and Wood (2006) 
23. Ayub, A., Ashish, G.B., Anupam, K. C. and Aniket, K .B. (2012): Infection control practices in health care: Teaching and learning requirements of medical undergraduates Col Atul Kotwal, SM d,*, Air Cmde Ajoy Mahen e ${ }^{a}$ 2012, Armed Forces Medical Services (AFMS).

24. Feather, A., Stone, S. P., Wessier, A., Boursicot, K. A., and Pratt, C. (2000): 'Now please wash your hands': the hand washing behavior of final MBBS candidates. J Hosp Infect; 45: 62-64.

25. Barikani, A. (2012): Knowledge, Attitude and Practice towards Standard Isolation Precautions among Iranian Medical Students. Global Journal of Health Science; 4, 2. http://dx.doi.org/10.5539/gjhs.v4n2p142

26. Amin, T.T., Al Noaim, K.I., Bu Saad, M.A., Al Malhm, T.A., and Al Awas, M.A. (2013): Standard Precautions and Infection Control, Medical Students' Knowledge and Behavior at a Saudi University: The Need for Change.Global Journal of Health Science; Vol. 5, No. 4; 2013. Published by Canadian Center of Science and Education URL: http://dx.doi.org/10.5539/gjhs.v5n4p114

27. Askarian, M., Honarvar, B. and Tabatabaeeb, H. R., (2004): Knowledge, attitude and practice towards standard isolation precautions in Iranian medical students. J Hosp Infect; 58, 292-296. http://dx.doi.org/10.1016/j.jhin.20

28. Angelillo, I.F., Mazziotta, A. and Nicotera, G. (1999): Nurses and hospital infection control: knowledge, attitudes and behavior of Italian operating theatre staff. J Hosp Infect 1999; 42:105-112.

29. Quiros, D., Larson, L.E. and Susan, X. (2007): Dissemination of the CDC's Hand
Hygiene Guideline and impact on infection ratesColumbia University School of Nursing, New York, NY

30. Holtzmann, D., Chen, S., Zhang, S., Hsia, J., Rubinson, R., Yun Bao, F. and Mc Queen, DV.(2003): Current HIV/AIDSrelated knowledge, attitudes and practices among the general population in China: Implications for action. AID Sci Prev and Vacc Res; 3(1).

31. Assadian, O. (2009): Infection control practices among professionals in Shiaraz Dentistry School. Iran. Archives of Iranian Medicine; 12(1):p:48-51

32. Ronnie, M., Elaine, L., Cheng, B., Schwartz, A., Silva, K.and Kunzel, C.(2008): Hand hygiene among General practice doctors, A survey of Knowledge, attitude and practices. am Dent Assoc.;139:948-957.

33. Monsalve Arteagaa,* C.D., Martı'nez Balzanoa, A.C. and Carvajal De Carvajalb,M. (2007): Medical students' knowledge and attitudes

34. towards standard precautions at Faculty of Medicine, Adults Infectious Diseases Department, Caracas, Venezuela .E-mail address: liacma@gmail.com

35. Nobile, C. G., Montuori, P., Diaco, E. and Villari, P. (2002): Healthcare personnel and hand decontamination in Intensive Care uUnits: knowledge, attitudes and behaviour in Italy. J Hosp Infect; 51: 226-232

36. Kim, K. M., Kim, M. A., Chung, Y. S., \& Kim, N. C. (2001): Knowledge and performance of the universal precautions by nursing and medical students in Korea. Am J Infect Control; 29: 295-300 